\title{
ARTIGO
}

\section{A promoção da saúde na Constituição Federal de 1988}

\author{
Renata Fortes Itagyba ${ }^{1}$ | Vinicius Rocha Moço ${ }^{2}$
}

Como citar este artigo: ITAGYBA, Renata Fortes. MOÇO, Vinicius Roça. A promoção da saúde na Constituição Federal de 1988. Revista de Ciências do Estado. Belo Horizonte: v. 6, n. 1, e21941. ISSN: 2525-8036.

Resumo: O presente artigo é voltado à análise do entendimento de saúde na Constituição Federal de 1988 (CF88), investigando se o principal instrumento jurídico em vigência no Brasil contempla os princípios da Promoção da Saúde (PS), preconizados pela Carta de Ottawa. O conceito de PS transcende a estrita ideia de corpo saudável, defendendo também o desenvolvimento de políticas e programas de caráter preventivo, além de considerar os determinantes sociais que envolvem as questões em saúde. $O$ artigo analisa se há intersecção entre a CF88 e a PS, aprofundando a questão ao investigar se os sete princípios da PS - Ações Multiestratégicas, Concepção Holística, Empoderamento, Equidade, Intersetorialidade, Participação Social e Sustentabilidade - estão contemplados na Constituição Federal. A metodologia da pesquisa baseia-se em leituras bibliográficas e legislativas, tanto dos conceitos da PS quanto das referências à saúde na CF88. Como resultado, o artigo revela que a CF88 contempla, em muitos aspectos, a concepção moderna de PS. Em termos humanísticos, portanto, a CF88 e a PS parecem convergir, alinhando-se quanto aos princípios mais essenciais e entendendo a saúde como um direito social

\footnotetext{
${ }^{1}$ Doutora em Ciências da Saúde pelo programa de Saúde Global e Sustentabilidade da FSP-USP (2019). Professora da Universidade Estadual de Mato Grosso (2019). Acadêmica do curso de Medicina na Universidade Estadual de Mato Grosso (2018-2023). Atuou por 10 anos como Coordenadora e Especialista de Desenvolvimento Humano, Responsabilidade Social e Premiações Corporativas na empresa ClearSale. Mestre em Ciências da Comunicação (2013), Licenciada e Bacharel em Filosofia (2010), sendo todos os títulos obtidos pela Universidade de São Paulo (USP). Realizou intercâmbio nos Estados Unidos e participou de cursos complementares na Long Island University, em NY e NC (2008-2010). Ainda no campo educacional, desenvolveu ações voluntárias no Brasil e no exterior, como no Hospital da Cruz Vermelha em Rondebosch, na África do Sul, e no Hospital Sírio Libanês, em São Paulo.

${ }^{2}$ Advogado, Pós-Graduando em Direito Constitucional pela Faculdade Legale, Bacharel em Direito pela Faculdade de Direito da Universidade Presbiteriana Mackenzie (2018) e Bacharel em Sistemas de Informação pela Universidade de Mogi das Cruzes - UMC (2008). Em 2016, foi aprovado para fazer parte do Laboratório de Ciências Criminais do Instituto Brasileiro de Ciências Criminais (IBCCRIM). Participou de atividades jurídicas voluntárias em comunidades carentes, pelo Instituto Pro Bono, e ações humanitárias internacionais, como no Hospital da Cruz Vermelha na África do Sul. Para aprimoramento do inglês, realizou intercâmbio em Vancouver, no Canadá. Participou de programa de mobilidade na Faculdade de Direito da Universidade de Coimbra no primeiro semestre de 2018, no qual foi contemplado com bolsa de estudos.
} 
universal.

Palavras-chave: Promoção da Saúde. Constituição Federal de 1988. Direito à Saúde. Determinantes Sociais.

Recebido em 12.06.2020

Aprovado em 02.03.2021

Publicado em 10.03.2021

\section{INTRODUÇÃO}

A concepção de PS desse artigo assume como base teórica a visão de saúde preconizada na Carta de Ottawa, alinhando-se a uma perspectiva de saúde que considera os determinantes sociais que permeiam a vida dos indivíduos, e rompe com uma compreensão excessivamente biológica e técnica da saúde. Nesse sentido, a PS foi reconhecida como um componente fundamental dos sistemas de saúde desde a Declaração de Alma-Ata (1978), que defende a saúde para todos e o fortalecimento de um campo de práticas humanitárias em saúde (SILVA JÚNIOR, 2019, p. 03), menos médico-centrado e hospitalocêntrico.

Concomitantemente, em termos jurídicos, a saúde é reconhecida como um Direito Social ou Direito Humano de segunda dimensão, expressamente previsto pela CF88 e presente em diversas normas internacionais, como a Constituição da Organização Mundial de Saúde (1948) e o Pacto Internacional sobre Direitos Econômicos, Sociais e Culturais (1966).

Uma vez configurada como Direito Social, a saúde passa a demandar ações concretas do Estado e da sociedade para a sua efetivação (CANAVARRO, 2006, p. 35). O Programa Nacional de Imunização, criado na década de 1970, e a priorização das ações da Atenção Básica (AB) foram grandes avanços para a consolidação da saúde como um direito social. A implantação do PSF, por sua vez, representa um marco na incorporação da estratégia de atenção primária na política de saúde brasileira, e segue a doutrina de cuidados primários de saúde apresentados na conferência de Alma-Ata (1978). A criação do Sistema Único de Saúde (SUS), em 1988, trouxe inovações ao questionar, ainda mais, o modelo médico-centrado e hospitalocêntrico (ESCOREL, 2017, p. 170), alinhado à CF88, que é a norma norteadora das políticas públicas no Brasil.

O presente artigo agrega conceitos das Ciências da Saúde e das Ciências Jurídicas, e 
tem por objetivo investigar se os sete princípios da PS - Ações Multiestratégicas, Concepção Holística, Empoderamento, Equidade, Intersetorialidade, Participação Social e Sustentabilidade (ITAGYBA, 2019, p. 85) - estão contemplados na CF88.

Para a consecução do objetivo da pesquisa, o método de investigação utilizado foi a leitura bibliográfica e legislativa, tanto dos conceitos da PS quanto das referências à saúde na Constituição Brasileira vigente. Em termos de saúde, a definição teórica de PS do presente artigo ancora-se, principalmente, nos estudos de Dina Czeresnia (2019) e Paulo Buss (2009), especialistas na área. No âmbito do Direito, foram consultados os juristas Saulo Lindorfer Pivetta (2014) e Fernando Mussa Abujamra Aith (2019), além do próprio texto da Constituição Federal de 1988.

Após a leitura bibliográfica, o estudo esteve focado em analisar se a CF88 contempla o entendimento em saúde promovido pela PS, assim como os seus princípios, que essencialmente se ancoram em princípios humanitários e a favor do estilo de vida saudável que, segundo a Carta de Ottawa (ORGANIZAÇÃO MUNDIAL DA SAÚDE, 1986), envolve determinantes sociais - e transcende, portanto, os aspectos biológicos, - como a paz, a moradia, a educação, a alimentação e a justiça social.

Uma vez delimitados os conceitos de PS e do entendimento da CF88 sobre a saúde, revela-se de suma importância analisar se, e como, a PS apresenta-se no texto constitucional, de modo a pautar as ações de saúde no território nacional.

\section{O ENTENDIMENTO DA PROMOÇÃO DA SAÚDE}

A fim de entender a essência dos princípios da PS, torna-se necessário recorrer à historicidade do conceito. Inicialmente, a concepção de PS respaldou-se na ideia da prevenção da saúde para, posteriormente, englobar conceitos que transcendem a estrita ideia de precaução contra doenças (ITAGYBA, 2019, p. 49).

A conceituação de PS tem sido modificada desde a década de 1920, quando Winslow (1920) relacionou a saúde às condições de vida do indivíduo. A partir de então, conferências internacionais de saúde enfatizaram o caráter indissociável entre a saúde e os determinantes sociais que, de acordo com a Organização Mundial da Saúde (OMS), estão vinculados ao modo que as pessoas vivem e trabalham, considerando-se fatores econômicos, culturais e comportamentais (ITAGYBA, 2019, p. 25).

O principal objetivo das conferências foi incitar a debates e articular ações para a PS, considerando-a essencial para o desenvolvimento das nações e o bem-estar da população 
mundial. A Conferência Internacional sobre Cuidados Primários de Saúde (1978) representou o primeiro encontro com esse viés, em Alma-Ata, na República do Cazaquistão, remetendo à necessidade de uma ação articulada entre os governos, os profissionais da saúde e a comunidade mundial para promover a saúde de todos os povos do mundo (CZERESNIA, 2003, p. 79). Em seguida, em 1986, ocorreu a conferência de Ottawa (1986), com a temática Promoção da Saúde nos Países Industrializados e, após seu sucesso, conquistado principalmente a partir da Declaração de Ottawa, que visa ao acesso da saúde a todos e, especialmente, aos países considerados periféricos, houve uma sequência de reuniões periódicas, com o intuito de produzir um alinhamento em torno de uma mesma perspectiva de saúde (BOAVENTURA, 2016, p. 24). Nos anos seguintes, houve oito Conferências com propósitos similares: em Adelaide (Austrália, 1988), em Sundsvália (Suécia, 1991), em Jacarta (Indonésia, 1997), na Cidade do México (México, 2000), em Bancoque (Tailândia, 2005), em Nairóbi (Quênia, 2009), em Helsinque (Finlândia, 2013) e em Xangai (China, 2016). O Brasil também sediou a 22nd IUHPE World Conference on Health Promotion (2016) e, ainda hoje, a temática da Promoção da Saúde enfrenta discussões recorrentes, reinventando-se.

De modo geral, essas conferências aprimoraram e consolidaram os princípios da PS no cenário internacional (BURALLI et al., 2018, p. 4). Contribuíram, assim, para que o conceito tradicional de saúde cedesse espaço à valorização das relações entre a saúde e as condições de vida (CZERESNIA, 2019, p. 41). Nesse sentido, pode-se afirmar que a PS ressignificou o conceito de saúde estabelecido até a década de 1980. Propôs a articulação entre os saberes técnicos e os populares, além da mobilização de recursos institucionais e comunitários, públicos e privados, para seu enfrentamento e resolução (ALMEIDA, 1998, p. 299).

Essa nova forma de entender saúde questiona o modelo biomédico e tecnicista, abrindo espaço para uma nova visão sobre saúde. Ampliou-se e consolidou-se a concepção de saúde-doença, com a valorização da relação de tipo equilíbrio-desequilíbrio do homem com o seu meio, o que inclui questões humanas, ecológicas e sociais (MENDES et al., 2006, p. 190). Nesse artigo, especificamente, tratamos de uma PS alinhada com a visão de saúde preconizada na Carta de Ottawa.

Reconhecendo essa tendência em saúde, o Ministério da Saúde brasileiro definiu, em seu glossário temático (BRASIL, 2013, p. 15), a PS como 
sociais, trabalhadores do setor sanitário e de outros setores, produzindo autonomia e corresponsabilidade.

O foco da PS volta-se ao atingimento de um perfil elevado de saúde, atrelando maior atenção às condições socioeconômicas de uma população, tanto na esfera individual quanto coletiva, e menor foco à perspectiva que reduz o conceito de saúde à ausência de doença, visando estritamente à recuperação ou à reabilitação.

A PS lida com um conceito mais amplo de saúde, que engloba questões políticas, econômicas e comportamentais, para além dos aspectos biológicos (MENDES et al., 2006, p. 190), mas sem desconsiderá-los. Trata-se de valorizar

as formas de organização da vida cotidiana, da sociabilidade, da afetividade, da sensualidade, da subjetividade, da cultura e do lazer e das relações com o meio ambiente (...) e é antes resultante do conjunto da experiência social, individualizada em cada sentir e vivenciada num corpo que é também, não esqueçamos, biológico (VAITSMAN, 1992, p. 171).

Ademais, há um viés político no conceito de PS, agregando ao campo, antes caracterizado por uma lógica sanitarista e curativa, os conceitos de democracia, movimentos sociais e políticas públicas (CARVALHO, 2004, p. 1088).

Atualmente, há diversos ataques ao direito à saúde, que desencadearam, inclusive, alterações constitucionais, como a EC 95/2016. A partir da Emenda Constitucional de número 95, institui-se um novo modelo fiscal para vigorar nos próximos vinte anos, com corte de gastos sociais, o que inclui o campo da saúde. Essa proposta gerou protestos da sociedade civil, sendo a causa de greves e ocupações estudantis que ocorreram nas escolas e universidades públicas em todo o Brasil (MARIANO, 2017, p. 259).

\section{OS PRINCÍPIOS DA PROMOÇÃO DA SAÚDE}

A PS apresenta sete princípios fundamentais, que são (1) Ações Multiestratégicas, (2) Concepção Holística, (3) Empoderamento, (4) Equidade, (5) Intersetorialidade, (6) Participação Social e (7) Sustentabilidade (ITAGYBA, 2019, p. 85). A partir desses pressupostos, pretende-se enfrentar a complexidade do processo saúde-doença por meio da ação integrada, multidisciplinar e intersetorial com participação popular.

A Carta de Ottawa (ORGANIZAÇÃO MUNDIAL DA SAÚDE, 1986) é um dos documentos precursores dessa visão transformadora de saúde e consolidou os princípios de PS supracitados. O documento descreve a essência da PS, incluindo aspectos como a transformação das condições de vida dos mais desfavorecidos, a defesa do envolvimento da população nas decisões, o prestígio das ações intersetoriais e a manutenção de ações em longo prazo. 
Trabalhando princípio a princípio, a Equidade é entendida como um conceito político e divide-se em horizontal, quando há tratamento igual para indivíduos iguais, e vertical, quando ocorre tratamento desigual para indivíduos diferentes (JACQUES, 2018, p. 34), o que pressupõe a destinação de diferentes recursos para diferentes níveis de necessidades.

Ademais, a Equidade é vinculada à justiça e revela a necessidade de se considerar os contextos diferentes e a identificação de assimetrias, combatendo-as. A Equidade refuta, antes de tudo, a disparidade mundial, e preconiza que uma comunidade saudável seria aquela capaz de entender os determinantes e condicionantes da desigualdade e da miséria (BOAVENTURA, 2016, p. 28), buscando maneiras de estabelecer um desenvolvimento sustentável também em termos de saúde.

O exercício da equidade também mitiga o aspecto nocivo do maquinário capitalista dos últimos anos, que tem submetido a sociedade à sociedade à austeridade fiscal e tensionado a garantia dos direitos à saúde (SCHENKMAN, 2019, p. 4459). Assim, a equidade também pretende que a reestruturação das economias ao longo de cadeias produtivas globais seja menos desigual (ROSSI et al., 2018, p. 106).

A Equidade é, ademais, uma vertente que valoriza o Estado, mediante o incentivo de políticas públicas que garantam a distribuição de bens e serviços e, dessa forma, minimizem o efeito das loterias biológica e social, distribuídas no ato do nascimento (FORTES, 2015, p. 153). A mitigação das discrepâncias sociais é um imperativo do princípio da Equidade e é possível a partir da consideração dos determinantes sociais da saúde, que extrapolam o viés estritamente curativo de doenças, entendendo a saúde como um fenômeno produzido socialmente.

A noção de Equidade é ainda mais importante no atual contexto de globalização, que potencializa iniquidades e perpetua as diferenças econômicas inter e intra países, com manutenção da pobreza (FORTES; RIBEIRO, 2014, p. 370). Afinal, considerando-se não apenas o campo individual, mas também o coletivo, a globalização vigente acentua as disparidades no campo da saúde, especialmente nos países mais excluídos dos circuitos centrais da economia mundial.

Nesse sentido, pela Equidade entende-se que é importante a verificação dos condicionantes que ultrapassem as questões biológicas em saúde e que diminuam as desigualdades mundiais. Dessa forma, oportunidades iguais de acesso aos recursos serão possíveis, tal como o estabelecimento de políticas de saúde universais em países com disparidade social, como o Brasil, que é um dos países mais desiguais do mundo (DWECK et al., 2020, p. 07). 
A partir da Carta de Ottawa, a PS também englobou a Participação Social, que confere ao povo maneiras de assegurar maior controle e melhorias sobre a sua própria saúde (ITAGYBA, 2019, p. 27). A Participação Social incita à capacitação das pessoas para uma gestão mais autônoma da saúde e permitindo que migrem da heteronomia à autonomia, da técnica à ética, da razão à emoção, do instituído ao instituinte (MENDES et al., 2016, p. 269).

A Carta de Ottawa reforça a relevância do processo de capacitar pessoas e populações para que sejam protagonistas em seus cuidados de saúde a partir da implantação de ações participativas, holísticas e intersetoriais. Nesse sentido, a Participação Social é entendida como o envolvimento de atores diretamente interessados no estabelecimento de prioridades, tomadas de decisões e avaliação de iniciativas. Ademais, a Participação Social incita a habilidade da negociação e aumenta a coesão entre indivíduos, promovendo mudanças nas condições de saúde a partir de novos recursos e menos desigualdade (MARIANO, 2017, p. 261).

Na lógica de Participação Social, a autora Wallerstein (2020, p. 380) defende a ideia de engajamento, que significa o envolvimento ativo dos indivíduos e da coletividade na produção e cocriação de oportunidades, processos e resultados. Assim, a complexidade da saúde e as questões socioambientais exigem um processo de capacitação e fortalecimento dos indivíduos e grupos sociais.

Ademais, atrela-se à ideia o conceito de Empoderamento, que é o poder para atuar em transformações psicossociais, políticas e culturais (VASCONCELOS, 2017, p. 32). Empoderar significa dar voz aos indivíduos e, a partir do conflito de ideias, fazer com que o outro perceba que há possibilidade de escolha, de modo a questionar os determinantes sociais (ITAGYBA, 2019, p. 33). O Empoderamento é, portanto, intimamente ligado à participação comunitária, visando à consolidação de espaços de diálogos e, principalmente, à criação de consciência quanto aos direitos sociais (WALLERSTEIN, 2020, p. 392).

$\mathrm{O}$ conceito tem sido utilizado em vários campos profissionais $\mathrm{e}$ interdisciplinarmente, com diferentes alcances e definições. O termo tem raízes nas lutas pelos direitos civis, no movimento feminista e na ideologia da ação social do século XX. Neste artigo, o Empoderamento

refere-se à habilidade do sujeito em ganhar conhecimento e controle sobre forças pessoais, sociais, econômicas e políticas para agir na direção da melhoria da sua situação de vida, podendo ser entendido na forma individual, organizacional e comunitária (BUSS, 2003, p. 19).

Trata-se de reconhecer as pessoas como sujeitos sociais que devem lidar com o resultado de suas escolhas e de suas intervenções (ITAGYBA, 2009, p. 33), e conceder 
autonomia para que sejam capazes de promover mudanças mais efetivas em suas realidades. É, resumidamente, um processo de diálogo em que se converte de sujeito passivo em ator participativo.

Outro princípio da PS é a Intersetorialidade, entendida como a responsabilidade múltipla entre vários setores para promover a saúde, combinando ações do Estado, do setor público, da esfera privada e da sociedade civil. Em um segundo sentido, a Intersetorialidade também pode significar o envolvimento de outras disciplinas e campos de conhecimento para a PS, de modo a produzir interdisciplinaridade (SOUSA et al., 2017, p. 1783).

No primeiro sentido, a Intersetorialidade aponta para a coordenação entre setores, caracterizando ações de saúde preconizadas por uma diversidade de atores globais (MACHADO, 2012, p. 12). Busca-se, portanto, a articulação de parcerias e atuações intersetoriais, a partir da convergência de esforços em torno das necessidades sociais. Para isso, a PS aposta continuamente na corresponsabilidade entre as várias esferas da saúde, impulsionando a formação de alianças, o que implica desbravar outras maneiras de relacionamento entre os agentes a partir de lógicas distintas de atuação em torno de objetivos comuns, preconizando a manutenção da identidade e do horizonte acerca de suas missões institucionais (MADEIRA; REICHER, 2003, p.184).

As lógicas de governo, de mercado e da sociedade civil podem ser entendidas como complementares e necessárias para a perenidade das ações implantadas. Logo, a frente de atuação pode reunir ações do Estado (políticas públicas saudáveis), da comunidade (reforço da ação comunitária), de indivíduos (desenvolvimento de habilidades pessoais), do sistema de saúde (reorientação do sistema de saúde) e de parcerias intersetoriais, visando à maior qualidade de vida para a população (BUSS, 2003, p. 25).

Ademais, a Intersetorialidade pressupõe ações multiprofissionais e interdisciplinares. Harmoniza-se, assim, a dicotomia existente entre o sujeito x coletivo, público x privado, Estado x sociedade, e os vários setores do conhecimento, a fim de romper as fragmentações na saúde e buscar o cuidado integral (VASCONCELOS, 2017, p. 40).

No segundo sentido pressupõe-se a articulação entre saberes e experiências de planejamento, e o envolvimento de diversos setores para a melhoria em saúde, entre os quais, o legislativo, a habitação, o serviço social, o trabalho, a alimentação, e o lazer. Promover saúde, nesse aspecto, é fazer com a saúde dialogue com as diversas áreas e outros campos do saber.

Para a operacionalização da interdisciplinaridade, recorre-se a um viés multiestratégico, que busca unir diferentes disciplinas e combinar diferentes abordagens, 
preconizando

o envolvimento de diferentes disciplinas e dizem respeito à combinação de métodos e abordagens variadas, incluindo desenvolvimento de políticas, mudanças organizacionais, desenvolvimento comunitário, questões legislativas, educacionais e do âmbito da comunicação (SíCOLI et al., 2003, p. 103).

As ações multiestratégicas remetem à viabilidade prática das ações em saúde, propondo abordagens que considerem a complexidade e a abrangência das questões envolvidas. Referem-se ao modo de concretização das práticas, orientadas pela Intersetorialidade, por meio de uma série de estratégias, de frentes variadas, capazes de responder com maior empenho à complexidade do problema.

Há, assim, inovação na maneira de construir atividades interdisciplinares voltadas à PS. Almeja-se, com isso, transformar as condições de vida das pessoas (CZERESNIA, 2019, p. 37), principalmente a partir da elaboração e da implantação de políticas públicas intersetoriais.

Por fim, o princípio da Sustentabilidade, no contexto das intervenções de saúde, é definida pela manutenção, ao longo do tempo, de uma intervenção ou de suas atividades no âmbito organizacional e/ou comunitário para alcançar os resultados desejados em saúde.

Ademais, a Sustentabilidade está ligada a iniciativas que estejam de acordo com o desenvolvimento sustentável e que garantam um processo duradouro e forte (ZIGLIO et al., 2000, p. 143). Mais que a adequação do termo ao sentido ambiental, esse princípio alinha-se ao desenvolvimento em longo prazo e trata da capacidade de continuidade das ações de PS (OCKÉ-REIS, 2018, p. 2038).

O termo Sustentabilidade, portanto, vincula-se à manutenção adequada da intervenção após o período inicial da implantação. A continuidade das ações deve ser avaliada, pois as iniciativas de saúde são de natureza complexa e, no cenário ideal, devem promover transformações sociais no médio e no longo prazo (OCKÉ-REIS, 2018, p. 2036).

Essa questão representa um enorme desafio para área da saúde, uma vez que a Sustentabilidade não se constitui, atualmente, como uma questão sobre a qual atores governamentais e sociais concentrem a sua atenção da forma devida.

\section{$4 \quad$ O DIREITO À SAÚDE NA CONSTITUIÇÃO FEDERAL DE 1988}

Uma vez apresentados os conceitos e os princípios da Promoção da Saúde, a partir de agora passa-se a investigar como o direito à saúde foi positivado na Constituição Federal de 1988. A Carta Magna elenca o direito à saúde em seu artigo $6^{\circ}$, classificando-o como um direito fundamental social: 
Art. $6^{\circ}$ São direitos sociais a educação, a saúde, a alimentação, o trabalho, a moradia, o transporte, o lazer, a segurança, a previdência social, a proteção à maternidade e à infância, a assistência aos desamparados, na forma desta Constituição (BRASIL, 1988).

Além disso, inclui a saúde entre os direitos previstos na seguridade social, conforme preconizado no artigo 194:

Art. 194. A seguridade social compreende um conjunto integrado de ações de iniciativa dos Poderes Públicos e da sociedade, destinadas a assegurar os direitos relativos à saúde, à previdência e à assistência social (BRASIL, 1988).

Uma vez classificado como direito fundamental social, o direito à saúde demanda prestações materiais do Estado para a sua efetivação. Conforme esclarecido por Aith (2006, p. 101), o Direito à saúde é reconhecido como um direito social e exige uma interação viva entre Estado e sociedade, voltada ao constante desenvolvimento das condições que possibilitarão acesso universal à saúde, ou seja, por meio da implementação de ações e políticas públicas que busquem atender às necessidades sociais.

Porém, Pivetta (2014, p. 39) ressalta que os direitos sociais, chamados também de direitos de segunda dimensão, podem assumir características defensivas, demandando que o Estado se abstenha de intervir nas liberdades dos indivíduos, características essas tradicionalmente associadas aos direitos de liberdade, ou de primeira dimensão. Ou seja, o direito fundamental social à saúde também pode impedir que o Estado adote medidas que cerceiam a liberdade do indivíduo.

Sarlet e Figueiredo (2008, p. 6) citam como exemplo da dimensão defensiva do direito à saúde as normas penais de proteção à vida, à integridade física, ao meio ambiente, à saúde pública e de vigilância sanitária. Por sua vez, Pivetta (2014, p. 41) exemplifica que um cidadão brasileiro que possui plano de saúde e que nunca utilizou o Sistema Único de Saúde (SUS) poderia até querer que o Estado lhe oferecesse todos os tratamentos e medicamentos de que precisa; contudo, como já desfruta de uma boa cobertura privada contra doenças, é plausível que enfatize o aspecto negativo do direito social.

Logo, tanto os direitos de liberdade quanto os direitos sociais podem apresentar, a depender do caso, características defensivas, demandando do Estado que não intervenha nas liberdades individuais, ou características prestacionais, de modo a necessitar implementação de ações ou políticas públicas por parte do Estado para a sua efetivação.

No entanto, realizando-se apenas a leitura do dispositivo mencionado, pouco pode ser extraído sobre o conteúdo e os contornos do direito à saúde. O referido direito ganha maior densidade nos artigos 196 a 200, que compõem a Seção II (Da Saúde) do Capítulo I do Título VIII (Da ordem social), e tratam especificamente do direito à saúde. Segundo o artigo 196: 
Art. 196. A saúde é direito de todos e dever do Estado, garantido mediante políticas sociais e econômicas que visem à redução do risco de doença e de outros agravos e ao acesso universal e igualitário às ações e serviços para sua promoção, proteção e recuperação (BRASIL, 1988).

Além disso, a CF88: considera as ações e serviços de saúde como de relevância pública, podendo ser executados pelo próprio Estado ou por terceiros (artigo 197); prevê a criação do SUS (artigo 198), definindo algumas de suas competências (art. 200); e garante a participação da iniciativa privada nos serviços de saúde (artigo 199).

No entanto, observa-se que, ainda que tenha dado maior densidade ao direito à saúde, o artigo 196 não precisou rigorosamente todas as posições jurídicas que podem ser extraídas do direito à saúde. Há inúmeras maneiras de se proteger e promover a saúde. A aparente baixa densidade do direito à saúde ocorre intencionalmente em razão da existência de variados fatores que devem ser considerados para o delineamento de seu conteúdo (PIVETTA, 2014, p. 57-58). Segundo Pivetta (2014, p. 58-59) o direito à saúde se relaciona a inúmeras variáveis, que muitas vezes não são previamente identificáveis, como avanços tecnológicos, surtos epidemiológicos ou modificações estruturais da sociedade.

Reforçando a tese da interdependência e mútua conformação de todos os direitos humanos e fundamentais, a proteção da saúde, individual e coletiva, está relacionada à proteção de uma série de outros direitos e interesses tutelados pelo sistema constitucional como, por exemplo, a vida, a dignidade da pessoa humana, o ambiente, a moradia, a privacidade, o trabalho, a propriedade, a seguridade social, etc (SARLET; FIGUEIREDO, 2008, p. 3). Assim, ainda que não tivesse sido positivado explicitamente no texto constitucional, o direito à saúde poderia ser admitido como direito fundamental implícito, pois uma ordem constitucional que protege os direitos à vida, à integridade física e ao meio ambiente sadio e equilibrado evidentemente deve salvaguardar a saúde, sob pena de esvaziamento daqueles direitos (SARLET; FIGUEIREDO, 2008, p. 5).

\section{A PROMOÇÃO DA SAÚde SOB A PERSPECTIVA DA CONSTITUIÇÃo FEDERAL DE 1988}

Observa-se que a CF88 abarca uma concepção ampla de saúde. Os marcos legais e institucionais da PS no Brasil dialogam com a I Conferência Internacional sobre Promoção da Saúde, realizada em Ottawa (1986). No mesmo ano, houve no país a VIII Conferência Nacional de Saúde e, considerando-se o contexto histórico de redemocratização, contou com intensa participação de profissionais, gestores e cidadãos. O ideário em saúde proposto 
aproximou-se dos conceitos centrais da PS e foi incorporados à Constituição Federal de 1988, outorgada pela Assembleia Nacional Constituinte (BUSS, 2009, p. 2306).

Desse modo, é possível inferir que a CF88 se adequa às premissas da PS, alinhandose à concepção mais abrangente do direito à saúde, conforme propugna a OMS, e compreendendo as dimensões preventiva e promocional na tutela jusfundamental. Nesse sentido, não basta falar em direito à saúde, mas no direito à proteção e à promoção da saúde (SARLET; FIGUEIREDO, 2008, p. 8).

Os princípios da PS se mostram presentes no texto constitucional. Conforme já mencionado, a PS possui sete princípios: Ações Multiestratégicas, Concepção Holística, Empoderamento, Equidade, Intersetorialidade, Participação Social e Sustentabilidade (ITAGYBA, 2019, p. 29).

A Equidade se faz presente no artigo 196 da CF88, ao ser mencionado o "acesso universal e igualitário às ações e serviços para sua promoção, proteção e recuperação", bem como no caput do artigo $5^{\circ}$ que garante que "todos são iguais perante a lei, sem distinção de qualquer natureza, garantindo-se aos brasileiros e aos estrangeiros residentes no País a inviolabilidade do direito à vida, à liberdade, à igualdade, à segurança e à propriedade" (BRASIL, 1988).

O texto constitucional prevê o tratamento isonômico pela lei, vedando-se diferenciações arbitrárias. Logo, são possíveis tratamentos diferenciados a indivíduos em condições desiguais, desde que tais diferenciações estejam de acordo com os princípios e valores constitucionais, observando-se critérios proporcionais, razoáveis e justificáveis. Oferecer tratamento isonômico às partes significa "tratar igualmente os iguais e desigualmente os desiguais, na exata medida de suas desigualdades" (NERY JÚNIOR, 1999, p. 42).

A Participação Social também está explícita na CF88, em seu artigo 198, inciso III, segundo o qual:

Art. 198. As ações e serviços públicos de saúde integram uma rede regionalizada e hierarquizada e constituem um sistema único, organizado de acordo com as seguintes diretrizes:

$[\ldots]$

III - participação da comunidade (BRASIL, 1988).

Já o artigo 77 do Ato das Disposições Constitucionais Transitórias prevê que os recursos públicos destinados às ações e serviços públicos de saúde serão acompanhados e fiscalizados por Conselhos de Saúde, constituindo-se assim uma Democracia Sanitária (AITH, 2006, p. 369). 
A participação da comunidade se dá de várias formas, indo desde formulações de propostas de políticas públicas de saúde até o próprio financiamento do sistema, conforme explicado por Sarlet e Figueiredo (2008, p. 14):

Além disso, o SUS se caracteriza pela participação direta e indireta da comunidade,
tanto no que respeita à definição, quanto relativamente ao controle social das ações e
políticas de saúde. Essa participação se realiza por meio dos representantes da
sociedade civil junto às sucessivas Conferências de Saúde, que têm competência
para fazer proposições às políticas de saúde em cada um dos níveis da federação
(cujo modelo mais marcante permanece sendo a VIII Conferência Nacional de
Saúde, ainda antes de 1988); perante os Conselhos de Saúde, que atuam no
planejamento e controle do SUS, aí incluído o financiamento do sistema, bem como
na viabilização de um canal para a participação popular, com a análise de propostas
e denúncias; e, ainda, no âmbito das agências reguladoras (Agência Nacional de
Vigilância Sanitária - ANVISA, Câmara de Saúde Suplementar da Agência Nacional
de Saúde Suplementar - ANS, Conselho Nacional de Meio Ambiente - CONAMA,
etc.).

O Empoderamento está atrelado à participação social, de modo que com a participação dos indivíduos no desenvolvimento de políticas públicas acabam obtendo maior controle sobre os fatores pessoais, sociais, econômicos e ambientais que impactam a saúde. Uma participação ativa das comunidades dá voz aos indivíduos e enseja a criação de consciência quanto aos seus direitos sociais.

A Intersetorialidade também se faz presente no texto constitucional nos dois sentidos supracitados. No sentido da combinação de ações do setor público, da esfera privada e da sociedade civil, o artigo 197 da CF88 garante a possibilidade de execução dos serviços de saúde por "pessoa física ou jurídica de direito privado" (BRASIL, 1988). Além disso, o artigo 199 menciona que "a assistência à saúde é livre à iniciativa privada" (BRASIL, 1988).

Por sua vez, no segundo sentido, o envolvimento de outras disciplinas e campos de conhecimento, conforme mencionado anteriormente, a Constituição Federal de 1988 abarca uma concepção ampla de saúde, o que reforça a tese da interdependência e mútua conformação de todos os direitos humanos e fundamentais. Sob a luz da CF88, a proteção da saúde, individual e coletiva, está relacionada à proteção de uma série de outros direitos, como a vida, a dignidade da pessoa humana, o ambiente, a moradia, a privacidade, o trabalho, a propriedade, a seguridade social, etc. (BRASIL, 1988)

As Ações Multiestratégicas estão relacionadas à concretização das práticas, orientadas pela Intersetorialidade, de modo a transformar as condições de vida das pessoas a partir da elaboração e da implantação de políticas públicas intersetoriais. Um exemplo de Ação Multiestratégica é o Programa Bolsa Família (PBF), que possui uma série de condições, entre elas: a permanência das crianças e adolescentes na escola; a adoção de cuidados básicos 
de saúde como vacinação, para crianças entre zero e seis anos, e agenda pré e pós-natal para gestantes e mães em amamentação (BUSS; CARVALHO, 2009, p. 2310).

O programa foi lançado pelo governo federal em 2013, consistindo na transferência condicional de renda destinada às famílias pobres que cumprissem com certas condições relacionadas à saúde e educação. Foi comprovado que o PBF teve impactos positivos tanto na economia quanto na saúde da população (DA FONSECA et al., 2018). O Programa Mais Médicos, criado em 2013, foi outra ação governamental exitosa ao enfrentar desafios que condicionavam a expansão e o desenvolvimento da Atenção Básica e, principalmente, a insuficiência e má distribuição de médicos (PINTO et al., 2017). Tais programas possuem relações diretas com a PS, uma vez que asseguram condições de vida e de acesso à saúde à população, com evidentes benefícios para a qualidade de vida comunitária (BUSS; CARVALHO, 2009, p. 2310).

O princípio da Sustentabilidade se refere à capacidade de continuidade das ações de PS, e se relaciona, entre outras coisas, com fontes de custeio que permitam a reprodução dos serviços ao longo do tempo. Uma vez incluídos à seguridade social, os serviços de saúde possuem sua fonte de custeio prevista no artigo 194 da CF88:

Art. 194. A seguridade social compreende um conjunto integrado de ações de
iniciativa dos Poderes Públicos e da sociedade, destinadas a assegurar os direitos
relativos à saúde, à previdência e à assistência social.
Parágrafo único. Compete ao Poder Público, nos termos da lei, organizar a
seguridade social, com base nos seguintes objetivos:
[...]
VI - diversidade da base de financiamento, identificando-se, em rubricas contábeis
específicas para cada área, as receitas e as despesas vinculadas a ações de saúde,
previdência e assistência social, preservado o caráter contributivo da previdência
social (BRASIL, 1988).

Além disso, os parágrafos $1^{\circ}, 2^{\circ}$ e $3^{\circ}$ do artigo 198 preveem regras específicas para o financiamento do SUS.

Por fim, a Concepção Holística da saúde demanda uma visão de todos os condicionantes de saúde que afetam o ser humano, relacionando-se com a visão ampla de saúde adotada pela CF88, englobando o direito à vida, à dignidade da pessoa humana, ao ambiente, à moradia, à privacidade, ao trabalho, à propriedade, à seguridade social, etc.

\section{CONSIDERAÇÕES FINAIS}

A PS supera o modelo biomédico e tecnicista, cedendo espaço para uma visão mais humanística em saúde. Com isso, ampliou-se e consolidou-se a concepção de saúde-doença, com a valorização da relação de tipo equilíbrio-desequilíbrio do homem com o seu meio, o que inclui questões socioculturais. 
Após a Carta de Ottawa, houve uma sequência de reuniões, que permitiu o alinhamento em torno de uma mesma perspectiva de saúde, aprimorando e consolidando os princípios da PS no cenário internacional e contribuindo para que o conceito tradicional de saúde cedesse espaço à valorização das relações entre a saúde e as condições de vida.

Logo, pode-se afirmar que a PS ressignificou o conceito de saúde estabelecido até a década de 1980. Após a leitura dos princípios da PS e da abordagem sobre saúde no texto constitucional, é possível afirmar que a CF88 contempla, em muitos aspectos, a concepção moderna de PS, que envolve a humanização em saúde.

Conforme relatado por Buss e Carvalho (2009, p. 2306), os membros da Assembleia Nacional Constituinte adotaram muitas diretrizes e princípios daquilo que foi chamado de "reforma sanitária brasileira", de modo que o texto final da CF88 incorporou elementos centrais da PS.

Ao abranger os sete princípios da PS, a CF88 contribui para o acesso a bens e serviços sociais que favoreçam o desenvolvimento de comportamentos favoráveis aos cuidados da saúde. A Constituição pode, com base nesses princípios, garantir a perenidade das ações em saúde, reunindo ações do Estado, da comunidade, de indivíduos, do sistema de saúde e de parcerias intersetoriais, para que estejam focadas na qualidade de vida da população (BRASIL, 1988). Ainda que possam existir hiatos importantes entre a teoria e a prática da PS, que por vezes é insuficiente no Brasil, é inegável que essas conquistas da PS ainda garantem mais benefícios do que vicissitudes à sociedade brasileira, e há espaço para melhorias contínuas (SOUSA, 2017, p. 1789).

Por fim, o alinhamento do texto constitucional a uma visão de saúde alinhada aos princípios da PS edifica a possibilidade de transformações sociais. Tautologicamente, ao contemplar os princípios da PS em seus fundamentos, a CF88 passa a ser instrumento importante na construção e na consolidação de uma mentalidade mais humanística em saúde, que considera os determinantes sociais que permeiam a vida das pessoas e das comunidades. Destarte, a intersecção entre os conceitos da PS e da CF88 é fundamental, uma vez que favorece a aplicação de políticas públicas focadas no desenvolvimento social e capazes de mitigar as desigualdades estruturais em saúde, que são historicamente enraizadas na realidade brasileira. 


\section{REFERÊNCIAS BIBLIOGRÁFICAS}

AITH, Fernando Mussa Abujamra. Manual de direito sanitário com enfoque em vigilância em saúde. 2019.

AITH, Fernando Mussa Abujamra. Teoria geral do direito sanitário brasileiro. 2006. Tese (Doutorado em Serviços de Saúde Pública) - Faculdade de Saúde Pública, Universidade de São Paulo, São Paulo, 2006. doi:10.11606/T.6.2006.tde23102006-144712. Acesso em: 2020-0331.

BRASIL. Constituição da República Federativa do Brasil 1988. Brasília. 1988. Disponível em: $<$ http://www.planalto.gov.br/ccivil_03/con stituicao/constituicaocompilado.htm>. Acesso em: 10 jun. 2020.

BOAVENTURA DSS. Para uma nova visão da Europa: aprender com o Sul. Sociologias, v. 18 , n. 43 , p. 24-56, 2016.

BURALLI, Rafael Junqueira et al. Moving Towards The Sustainable Development Goals: The Unleash Innovation Lab Experience. Ambiente \& Sociedade, v. 21, 2018.

BUSS, Paulo Marchiori; CARVALHO, Antonio Ivo de. Desenvolvimento da promoção da saúde no Brasil nos últimos 20 anos (1988-2008). Ciência e Saúde Coletiva (Impresso), v.14, p. 23052316, 2009.

BUSS, Paulo Marchiori. Uma introdução ao conceito de promoção da saúde. Promoção da saúde: conceitos, reflexões, tendências, v. 2, p. 19-42, 2003.

CANAVARRO, Maria Cristina et al. Desenvolvimento dos Instrumentos de Avaliação de Qualidade de Vida na Infecção VIH da Organização Mundial de Saúde (WHOQOL-HIV; WHOQOL-HIV-
BREF) para Português de Portugal: Apresentação de um Projecto. In: VI HIV/AIDS Virtual Congress: "Prevenção da SIDA: Um desafio que não pode ser perdido". SIDAnet: Associação Lusófona, 2006. p. 35-44.

CARVALHO, Sérgio Resende. Os múltiplos sentidos da categoria" empowerment" no projeto de Promoção à Saúde. Cadernos de Saúde Pública, v. 20, n. 4, p. 1088-1095, 2004.

CASTIEL, Luis David; CZERESNIA, Dina. Dédalo e os Dédalos: identidade cultural, subjetividade e os riscos à saúde. Promoção da saúde: conceitos, reflexões, tendências, p. 79 citation_lastpage $=95,2003$.

CZERESNIA, Dina. Simondon e os sentidos da individuação biológica. DoisPontos, v. 16, n. 2, 2019.

CZERESNIA, Dina; DE FREITAS, Carlos Machado (Ed.). Promoção da saúde: conceitos, reflexões, tendências. SciELOEditora FIOCRUZ, 2009.

DA FONSECA, Ana Maria Medeiros; ROQUETE, Claudio. Proteção social e programas de transferência de renda: Bolsa-Família. PROTEÇÃO SOCIAL E TRANSFERÊNCIA DE RENDA, 2018.

ESCOREL, Sarah et al. O Programa de Saúde da Família e a construção de um novo modelo para a atenção básica no Brasil. Revista Panamericana de Salud Pública, v. 21, p. 164-176, 2007.

FORTES, Paulo Antonio de Carvalho. Refletindo sobre valores éticos da Saúde Global. Saúde e Sociedade, v. 24, p. 152$161,2015$.

FORTES, Paulo Antônio de Carvalho; RIBEIRO, Helena. Saúde Global em 
tempos de globalização. Saúde e Sociedade, v. 23, p. 366-375, 2014.

HEIDMANN, Ivonete TS et al. Promoção à saúde: trajetória histórica de suas concepções. Texto \& ContextoEnfermagem, v. 15, n. 2, p. 352-358, 2006.

ITAGYBA, Renata Fortes. A Promoção da Saúde no Haiti por meio de organizações humanitárias. 2019. Tese (Doutorado em Saúde Global e Sustentabilidade) - Faculdade de Saúde Pública, Universidade de São Paulo, São Paulo, 2019. doi:10.11606/T.6.2019.tde27082019-111200. Disponível em $<$ https://teses.usp.br/teses/disponiveis/6/61 40/tde-27082019-111200/pt-br.php> Acesso em: 2020-03-30.

JACQUES, Nadège et al. Equidade na atenção à saúde de mulheres no Haiti. Revista Panamericana de Salud Pública, v. 41, p. 34, 2018.

MACHADO, Maria de Fátima Antero Sousa et al. Competências em promoção da saúde: o domínio parceria na residência multiprofissional em saúde. Revista Brasileira em Promoção da Saúde, v. 31, n. 4, 2018.

MARIANO, Cynara Monteiro. Emenda constitucional 95/2016 e o teto dos gastos públicos: Brasil de volta ao estado de exceção econômico e ao capitalismo do desastre. Revista de investigações constitucionais, v. 4, n. 1, p. 259-281, 2017.

MENDES, Rosilda; FERNANDEZ, Juan Carlos Aneiros; SACARDO, Daniele Pompei. Promoção da saúde e participação: abordagens e indagações. Saúde em Debate, v. 40, p. 190-203, 2016.

NERY JÚNIOR, Nelson. Princípios do processo civil à luz da Constituição Federal. Revista dos Tribunais, 1999.
OCKÉ-REIS, Carlos Octávio. Sustentabilidade do SUS e renúncia de arrecadação físcal em saúde. Ciência \& Saúde Coletiva, v. 23, p. 2035-2042, 2018.

ORGANIZAÇÃO MUNDIAL DA SAÚDE. Carta de Ottawa. Primeira conferência internacional sobre promoção da saúde. Ottawa. 1986.

PAIM, Jairnilson S.; ALMEIDA FILHO, Naomar de. Saúde coletiva: uma" nova saúde pública" ou campo aberto a novos paradigmas?. Revista de saúde Pública, v. 32, n. 4, p. 299-316, 1998.

PINTO, Hêider Aurélio et al. Programa Mais Médicos: avaliando a implantação do Eixo Provimento de 2013 a 2015. Interface-Comunicação, Saúde, Educação, v. 21, p. 1087-1101, 2017.

PIVETTA, Saulo Lindorfer. Direito fundamental à saúde: Regime jurídico, políticas públicas e controle judicial. São Paulo: Revista dos Tribunais, 2014. 272 p.

PRATA, Pedro Reginaldo. Desenvolvimento econômico, desigualdade e saúde. Cadernos de saúde pública, v. 10, p. 387-391, 1994.

ROSSI, P. L. (Org.) ; OLIVEIRA, A. L. M. (Org.) . Economia Pós-Pandemia: Desmontando os mitos da austeridade fiscal e construindo um novo paradigma econômico. 1. ed. São Paulo: Autonomia Literária, 2020.

ROSSI, P. L. (Org.) ; DWECK, E. (Org.) ; OLIVEIRA, A. L. M. (Org.) . Economia Para Poucos: impactos sociais da austeridade e alternativas para o Brasil. 1. ed. São Paulo: Autonomia Literária, 2018. 372p.

SARLET, Ingo Wolfgang; FIGUEIREDO, Mariana Filchtiner. Algumas considerações sobre o direito fundamental à proteção e promoção da 
saúde aos 20 anos da Constituição Federal de 1988. Revista de Direito do Consumidor, v. 67, p. 125-172, 2008.

SCHENKMAN, Simone; BOUSQUAT, Aylene Emilia Moraes. Alteridade ou austeridade: uma revisão acerca do valor da equidade em saúde em tempos de crise econômica internacional. Ciência \& Saúde Coletiva, v. 24, p. 4459-4473, 2019.

SÍCOLI, Juliana Lordello; NASCIMENTO, Paulo Roberto do. Promoção de saúde: concepções, princípios e operacionalização. InterfaceComunicação, Saúde, Educação, v. 7, p. 101-122, 2003.

SILVA JÚNIOR, Jarbas Barbosa da. Promoção da saúde: ação necessária e urgente nas Américas. 2019.

SOUSA, Marta Caires de; ESPERIDIÃO, Monique Azevedo; MEDINA, Maria Guadalupe. A intersetorialidade no Programa Saúde na Escola: avaliação do processo político-gerencial e das práticas de trabalho. Ciência \& Saúde Coletiva, v. 22, p. 1781-1790, 2017.

VAITSMAN, Jeni. Saúde, cultura e necessidades. In: Saúde coletiva?
Questionando a onipotência do social. 1992. p. 157-73.

VASCONCELOS, Eduardo Mourão. As abordagens anglo-saxônicas de empoderamento e Recovery (recuperação, restabelecimento) em saúde mental I: Uma apresentação história e conceitual para o leitor brasileiro. Cadernos Brasileiros de Saúde Mental/Brazilian Journal of Mental Health, v. 9, n. 21, p. 31-47, 2017.

WALLERSTEIN, Nina et al. Engage for equity: a long-term study of communitybased participatory research and community-engaged research practices and outcomes. Health Education \& Behavior, v. 47, n. 3, p. 380-390, 2020.

WALLERSTEIN, Nina. Powerlessness, empowerment, and health: implications for health promotion programs. American journal of health promotion, v. 6, n. 3, p. 197-205, 1992.

WINSLOW CEA. The untilled fields of public health. Science, 1920.

ZIGLIO, E.; HAGARD, S.; GRIFFITHS, $\mathrm{J}$. Health promotion development in Europe: achievements and challenges. Health Promotion International, v. 15, n. 2, p. 143-154, 2000.

\section{HEALTH PROMOTION IN THE 1988 FEDERAL CONSTITUTION}

Renata Fortes Itagyba | Vinicius Roça Moço

How to cite this article: ITAGYBA, Renata Fortes. MOÇO, Vinicius Roça. A promoção da saúde na Constituição Federal de 1988. Revista de Ciências do Estado. Belo Horizonte: v. 6, n. 1, e21941. ISSN: 2525-8036.

Abstract: This article focuses on the analysis of the understanding of health in the Federal Constitution of 1988 (CF88), investigating whether the main legal instrument in Brazil includes the principles of Health Promotion (PS). The concept of PS transcends the strict idea of a healthy body, also defending the development of preventive policies and programs, in addition to paying attention to the social determinants that involve health issues. The article 
analyzes whether there is an intersection between CF88 and PS, deepening the issue by investigating if the seven principles of PS - Multi-Strategic Actions, Holistic Conception, Empowerment, Equity, Intersectionality, Social Participation and Sustainability - are included in the Federal Constitution. The research methodology is based on bibliographic and legislative reviews, both of the concepts of PS and references to health in CF88. As a result, the article reveals that the CF88 contemplates, in many aspects, the modern conception of PS. In humanistic terms, therefore, CF88 and PS seem to converge, aligning themselves with the most essential principles and understanding health as a universal social right.

Keywords: Health Promotion. 1988 Federal Constitution. Right to Health. Social Determinants. 